\section{Prácticas amorosas en la escuela colombiana en la primera mitad del siglo XX: Apuntes para una historia del amor femenino}

\section{Love Practices in the Colombian School during the First Half of the Twentieth Century: Notes for a History of Feminine Love}

\author{
Práticas amorosas na escola \\ colombiana na primeira metade \\ do século XX: Apontamentos para \\ uma história do amor feminino
}

\section{Claudia Ximena Herrera Beltrán*}

* Doctora en Educación Universidad de Burgos, España. Profesora de planta de la Facultad de Educación, Departamento de Posgrado, Maestría en Educación de la Universidad Pedagógica Nacional, Colombia. Correo electrónico: cherrera@pedagogica.edu.co

\section{Resumen}

En América Latina cada vez más mujeres se distancian de representaciones de ellas establecidas por ciertos discursos de la modernidad; sin embargo, la contemporaneidad continúa mostrando relaciones desiguales, construcciones binarias de sexo y género y exclusión frente a cualquier asomo de resistencia. Frente a esa situación, este artículo de investigación muestra, a partir de un estudio arqueológico y genealógico, la manera en que el amor, como sentimiento y emoción, fue objeto de enseñanza para las niñas en la escuela colombiana durante la primera mitad del siglo xx. En ese sentido, se formula la pregunta por las emociones, los sentimientos y los discursos, y se pone al descubierto cómo se configuraron prácticas y se naturalizaron verdades que definen hasta hoy la forma de ser mujeres y hombres.

\section{Palabras clave}

Amor femenino; escuela; emociones; educación de los sentimientos

\section{Abstract}

In Latin America women increasingly detach themselves from feminine representations produced by certain discourses of modernity. However, unequal relations, binary constructions of sex and gender, and exclusion whenever there is any sign of resistance are still signs of contemporaneity. In response to this situation, this research paper shows, through an archaeological and genealogical study, how love, as a feeling and emotion, was a subject of education for girls in the Colombian school during the first half of the twentieth century. In that sense, the author reflects upon emotions, feelings and discourses, and reveals how society shaped practices and legitimized truths that, even today, define both men's and women's nature.

\section{Keywords}

Women's love; school; emotions; education of feelings

\section{Resumo}

Na América Latina cada vez mais mulheres se distanciam de representações estabelecidas sobre elas por certos discursos da Modernidade; contudo, a Contemporaneidade continua mostrando relações desiguais, construções binárias de sexo e gênero y exclusão frente a qualquer tentativa de resistência. Diante dessa situação, neste artigo de investigação procura-se mostrar, a partir de um estudo arqueológico e genealógico, a maneira pela qual o amor, em quanto sentimento e emoção, foi objeto de ensino para as meninas na escola colombiana durante a primeira metade do século xx. Nesse sentido, a pesquisadora perguntar-se pelas emoções, pelos sentimentos e pelos discursos, e põe ao descoberto como foram configuradas práticas e naturalizadas verdades que até hoje definem a forma de ser mulheres e homens.

\section{Palavras-chave}

Amor feminino; escola; emoções; educação dos sentimentos

Fecha de recepción: febrero 26 de 2016

Fecha de aprobación: abril 26 de 2016 


\section{Introducción}

$\mathrm{L}$ lorar al esposo desaparecido, guardar luto, experimentar largas temporadas de dolor o morir de amor hablarán de la emergencia del amor romántico en el siglo XIX. No es que el amor no existiera, señala Badinter (1891), es que no tenía ni la condición ni la importancia que le atribuimos hoy. El hoy urge precisarlo puesto que una cosa es el amor romántico del siglo xIx y otro el del siglo xx, así como diferente fue el de la primera mitad, al igual que el de la segunda, y otra muy distinta es lo que viene aconteciéndole al amor del siglo xxI; Bauman (2009), por ejemplo, va a denominar amor líquido a una nueva forma de amor, de presencia efímera, con vínculos frágiles y distantes al sufrimiento y al "amor fluyente" como la posibilidad concreta de dos sujetos en igualdad de condiciones que se sitúan en el presente y en tal sentido se relacionan. No obstante, ante este último planteamiento que cada vez parece cobrar más fuerza entre estudiosos y amantes de la contemporaneidad, valdría la pena preguntarse hasta qué punto y desde cuáles entramados sociales dicha producción fue posible. Si bien es cierto que en América Latina cada día son más las mujeres que se distancian de las representaciones con que los discursos de cierta modernidad las ha fundado, este tiempo que nos acontece sigue mostrándonos relaciones desiguales, construcciones binarias de sexo y género, y exclusión de cualquier asomo de resistencia al libreto que se les impone a muchas mujeres desde el momento mismo del nacimiento. Reconocemos que en esa forma de ser mujeres y hombres son varios los elementos que responden a una condición estructural que hace pervivir ciertas prácticas en medio de los cambios profundos que dichos roles parecen experimentar. En este artículo de investigación ${ }^{1}$ y antes de adentrarnos en cómo se dio la enseñanza del amor a las niñas en la escuela colombiana, nos permitimos hacer un rodeo para pensar el amor como una emoción y un sentimiento. En tal sentido, a continuación nos interrogaremos por ellas, por las emociones, los sentimientos y su emergencia en la modernidad y lo haremos a partir de un trabajo arqueológico y genealógico que pone en juego conceptos tales como fuerzas, discursos, enunciados, emergencia y que comprende el archivo como la configuración de enunciados tomados de discursos diversos que circulan en superficies docu-

1 Este artículo es producto de la investigación adelantada entre el 2013 y el 2014 en la Universidad Pedagógica Nacional a través del ciup. Se trata del proyecto "Educar los sentimientos: discursos en torno al amor y la mujer en la educación en Colombia (final siglo XIX-comienzos del siglo Xx), en compañía de la profesora Carolina Ojeda. mentales, ellos no se escogen y leen desde jerarquías más allá de cumplir con el propósito de "decir" algo que circuló en la época escogida. Esos discursos se constituyen en voces a modo de enunciados que van configurando ciertas verdades que se naturalizan. Se trata entonces de hacer la historia de los discursos en torno al sentimiento amoroso, emoción susceptible y necesaria de ser educada desde la escuela y a las niñas especialmente en el marco de ciertas condiciones de posibilidad.

\section{Sentimientos, emociones y amor}

El advenimiento de la modernidad trajo consigo un relato sobre las emociones, aunque no se equiparasen a las ciencias (Illouz, 2007), por ejemplo Weber, Marx, Simmel, Durkheim y Mauss aportan con sus discursos elementos que muestran una emocionalidad particular en el marco de las condiciones históricas y sociales de la época en cuestión. Conceptos como alienación, reserva, frialdad, indiferencia y solidaridad así como la relación de las emociones con lo cognitivo se encuentran circulando por registros variados. Por ejemplo, las emociones como angustia, amor, competitividad, indiferencia, culpa, van a dotar a las relaciones modernas de tensiones desde sentidos distintos (Illouz, 2007). Y son además producciones discursivas desde la filosofía, la economía, la psicología y la sociología permeando todos los intersticios de la existencia humana occidental. Así, las emociones son una invención al decir de Illouz del hombre sentimental: Homo Sentimentalis.

La autora afirma que "la emoción no es una acción per se, sino que es la energía interna que nos impulsa a un acto, lo que da cierto carácter y colorido a un acto", y "que implica al mismo tiempo cognición, afecto, evaluación, motivación y el cuerpo" (Illouz, 2007). Es decir que viene de adentro y dota lo exterior de unas ciertas características. Dicha acción resulta en un doble efecto: se expresa desde, en y a través del cuerpo, en una acción única, dotada de ciertas características que produce el entorno rodeándola de una energía que se torna en acciones para ser devuelta, que a su vez desencadena otra desde el mismo sujeto que las pone en acción en primera instancia y que recibe esa nueva energía producida en el exterior. Dichas emociones son culturales y sociales, en consonancia con ello, históricas y a la vez personales. Esto último permite decir que las emociones se constituyen a la vez de cultura y de sociedad, lo que les confiere una profunda internalización e irreflexión en la acción (Illouz, 2007). De algún modo se constituyen en naturales y les confieren a 
las relaciones unos modos de expresión inalterables que se intentan reproducir en su homogeneidad y permanencia.

De otro lado, las disposiciones sociales son también disposiciones emocionales: "la distinción y la división más fundamentales que organizan la mayor parte de las sociedades del mundo es decir entre hombres y mujeres se basan y se reproducen a través de las culturas emocionales" (Illouz, 2007). Las emociones se organizan de modo jerárquico y, a su vez, este tipo de jerarquía emocional organiza implícitamente las disposiciones sociales y morales. En este punto cabe preguntarse por la escuela como institución social en la que las emociones cobran sentido particular por ser el lugar de su enseñanza, reproducción, control y administración como lo es la familia.

La tesis de la conferencia primera del libro que estamos referenciando se ocupa de mostrar lo que acabamos de señalar, cuando afirma que el capitalismo se hizo de la mano de la construcción de una cultura emocional muy especializada, que entre otras cosas llevó a hombres y mujeres de la clase media a centrarse fuertemente en su vida emocional tanto en el trabajo como en la familia (Illouz, 2007). A partir de lo anterior diremos que la escuela es una institución social, productora y reproductora de una emocionalidad al servicio del proyecto capitalista, en el cual el progreso se alcanza a partir del cumplimiento de los roles como miembros de una sociedad, en el orden a unas jerarquías establecidas. Esta dinámica emocional en la primera mitad del siglo xx en Colombia reconfiguró los ámbitos privado y público de manera importante; el yo fue ampliamente considerado desde ambos. El sujeto (el yo) en su constitución se hizo visible como nunca antes.

Situar desde Illouz (2007), la fuerza del discurso psicoanalítico de Freud y también de sus seguidores, disidentes y otros psicólogos ayuda a reconocer dicho aporte en la configuración de la vida emocional de los sujetos en el siglo XX, que ella nombra como "El estilo emocional". Es decir que la etiología y morfología de las emociones, así como sus técnicas para comprenderlas y manejarlas se erigieron fuertemente en esta época, lo que no significa que no hubiese habido antes unos modos de este estilo emocional; recordemos, por ejemplo, que el amor romántico surgió en el siglo XIX, por nombrar alguno. Pero si ese estilo se configuró a partir de la terapia psicoanalista, como señala Illouz, cabe preguntarse ¿cómo se consolidó en Colombia, cuando el psicoanálisis fue escasamente apropiado? ¿De qué modo fue constituyéndose un estilo emocional en el país? Ideas como la familia, el dispositivo de alianza, la problematización de la normalidad y la sexualidad que Freud puso a funcionar y que, al decir de Illouz (2007), transformaron de manera importante la sociedad estadounidense y construyeron el yo; no todas entraron al país por vía de fuerzas como la Iglesia católica y el saber psicológico referido principalmente a la infancia. Por ejemplo el tema de la sexualidad - y su abordaje desde el pensamiento freudiano- aparece censurado especialmente y tratado en escasos documentos, sin embargo fue el pensamiento psicológico desde distintas tendencias el que circuló ampliamente. Lo permite y favorece un análisis profundo en cuanto al modo en que la psicología en torno a la cotidianidad se expresó en Colombia en múltiples discursos que los periódicos publicaron y que en clave de consejos tocaron la emocionalidad social como aconteció en Estados Unidos. El modo de ese discurso, su tono entre legal, experto y neutro se constituyó en científico y por lo tanto creíble, en especial para las mujeres. La llegada de un discurso psicológico más experimental que racional permeó instituciones y proyectos económicos y sociales. Las mujeres aportaron una sensibilidad en el trabajo que impulsó grandemente el desarrollo de la psicología social, en especial laboral, al decir de Ullouz, ya que configurar un ambiente de trabajo grato en el cual los sujetos se sintieran a gusto fue posible a partir de las investigaciones en torno al sentir de las mujeres en la fábrica, en la empresa; fenómeno extrapolado a la población trabajadora en general. Luego, la comunicación y la publicidad al lado de esta psicología reconocieron el valor del sentimiento en los procesos económicos productivos y de mercado. Podríamos arriesgarnos a señalar que lo que hoy se llama autoayuda emergió a partir de una emocionalidad que se hizo pública y que fue aprovechada desde la economía política, lo cual favoreció nuevos modos del sentimiento amoroso a finales del siglo $\mathrm{XX}$.

\section{La enseñanza del amor en las escuelas colombianas}

En la primera mitad del siglo xx en Colombia el cuerpo femenino se comenzó a visibilizar desde la enfermedad y la debilidad producto de una formación delicada y de poco movimiento. Las mujeres jóvenes eran proclives a morir, o a no responder con su más noble misión que era la de ser madres. Miguel Jiménez López, médico, educador, político e intelectual de la época expone esa condición lamentable en que vivía la mujer, y por la que era imperante introducir otra educación, 
Ya hemos hablado del nerviosismo con sus formas infinitas, de la clorosis y de sus lamentables complicaciones, de las dispepsias, las gastralgias, las úlceras de estómago, de la tuberculosis y de infinidad de otras afecciones que agostan las mejores juventudes; pero aun en ausencia de cualquiera de estos estados, la generalidad de nuestras damas son temperamentos hipersensibles, organismos frágiles incapaces de ninguna actividad sostenida, y quienes la menor impresión produce una crisis de nervios, y el más ligero esfuerzo da un desmayo; y si es que llega para ellas la ocasión de cumplir la más trascendental de sus misiones, cual es la de ser madres, ¿Qué puede esperarse de seres que han sido formados en medio de todas las delicadezas? La debilidad y la insuficiencia solamente. (Jiménez, 1910)

Estas mujeres débiles presentaban partos con dificultades, imposibilidad para lactar, efectos del alumbramiento con secuelas para toda la vida y una serie de problemas que ponían en riesgo su tarea como madres, no solo entendido desde la interioridad del hogar, sino desde el marco de la familia, que era sobre todo un referente de lo social. Un cuerpo débil podía llevar a la mujer a perderse en el vicio, arrastrando a otros a la enfermedad como al desbordamiento de sus pasiones. En consecuencia, la virtud se relacionaba con la higiene física de la mujer virtuosa en discursos sobre la degeneración de la raza, que explicaban la pobreza y el estado de atraso desde la suciedad y la indecencia, pero también los saberes modernos que enfatizaban en la salud y el movimiento, en busca de que los cuerpos se instalaran en las lógicas de la salud, la higiene y el movimiento (Del Real y Mijares, 1907). La mujer, por supuesto, no fue ajena a estos propósitos en los que se exaltó su misión maternal especialmente. Alcanzar este proyecto civilizatorio era posible desde una educación que se pensaba encaminando, entre otras cosas, la emotividad femenina -muchas veces desbordada-, mediante prácticas de disciplinamiento sustentadas desde saberes y poderes como la educación física, la economía doméstica, la urbanidad, la medicina, la psicología y la conducta.

Así la mujer desde el discurso educativo fungía de dos formas: una, como sujeto que recibía educación, a ello se debe el conjunto de premisas que fundamentaron la importancia de su educación, instrucción, formación, mientras se iban identificando más virtudes que no podían quedarse sin ser encauzadas debidamente (Toscano, 1920); dos, su acción como educadora, pues gracias a la educación en dichas virtudes, podía y estaba llamada a cumplir con esa noble función.
La premisa primera consistía en educarla para el hogar, esto es, para ser madre y esposa. Un recorrido por la legislación de comienzos de siglo xx sobre la instrucción pública femenina permite anotar cómo su inmersión en la educación desde esta apuesta fue cobrando fuerza. Al inicio fueron las prácticas de crianza y cuidado de los hijos, la puericultura y posteriormente la economía doméstica, la higiene, la culinaria, lo que constituyó el suelo de saber de esta educación. Se educaba a la mujer, como aquella persona pura en pensamientos, palabras y obras, que sacrificaba sus deseos y gustos por los de los demás, recompensada con el don del sufrimiento y fortalecida con las armas de la dulzura y el amor (Acosta, 1905).

De acuerdo también a su posición social, unas virtudes serían más naturales en unas que en otras, como las posibilidades de extender sus alcances. De este modo, era importante que la niña y la joven acomodadas ofrecieran el cuidado de los padres y ancianos, o como esposa de un hombre trabajador, participaran en la administración doméstica; mientras que en las niñas y mujeres de escasos recursos, la educación primaria se ocuparía de dotarlas con lo necesario para que en caso de no contraer matrimonio, su amor pudiera manifestarse en el trabajo o el magisterio.

En la segunda premisa la mujer era educada para cumplir dos roles: como maestra y como madre de sus hijos. Ambas formaban parte de la configuración de lo femenino desde el amor, desde el cual la mujer se hacía garante del bienestar en el hogar, y también en la sociedad y en sí misma.

Cuando se trataba de la educación de los hijos no se requería de "mucha erudición, ni grandes conocimientos científicos, sino religiosos, morales, pedagógicos e higiénicos" Monsalve (1897a). Su dotación natural de amor y ternura permitía que esta misión le resultara fácil, y cada una de sus acciones reflejara la consigna por el bien de quienes la rodeaban y la satisfacción de sí misma, instalada en su exterioridad.

Aquí se empezaba a regular el amor. Si este había sido conducido mediante la educación, la mujer también sabría cuándo debía entrar a corregir en nombre del amor. Conociendo que su amor desmedido podía ser responsable del crecimiento del niño sin la fuerza y los principios claros que requería la sociedad, debía contenerse. El cuidado, y esto va muy en consonancia con la pedagogía católica propia de ese momento, debía basarse en un amor compasivo, abnegado y en conformidad con el deber. De otro lado, se reconocía en los discursos que frente a las diferencias entre mujeres y hombres, aunque iguales en dignidad y dis- 
tintos por muchos aspectos, no era posible (a pesar de las opiniones en contra de distinguidos pedagogos) educarlos de idéntica manera y guiarse por el mismo ideal. De allí que existieran ideales distintos para la educación de cada sexo, fundados en la organización y en el destino de ambos. Sobresalían en el hombre unas facultades, en la mujer otras, y como una de las leyes más esenciales de la pedagogía es que se debía educar a cada individuo según las indicaciones de su propia naturaleza, no torciendo ni violentando ninguna facultad; de lo contrario se faltaba gravemente a todos los principios de la educación y a todas las leyes de la naturaleza (Jiménez, 1910).

En esa desigualdad aceptada, el sentimiento amoroso entró a conciliar las diferencias entre hombres y mujeres, si la mujer no podía en ninguna circunstancia rivalizar con el poder racional masculino, debía poner el relieve suficiente a sus facultades afectivas que le autorizaran a habitar el mundo del que el hombre era el dominador mediante su única y más grande posesión: el amor.

\section{¿Qué son los sentimientos?}

Las siguientes son posturas frente al sentimiento que el discurso deja ver. De acuerdo con (Pinilla, 1920): (1) Las emociones son experiencias sensibles momentáneas agradables o desagradables llamadas sentimientos. (2) Ellos forman parte de una sensibilidad moral producida a partir de objetos morales o intelectuales. (3) En la sensibilidad del niño están tanto las pasiones generosas y nobles como las pasiones perversas.

Las anteriores afirmaciones revelan en particular una postura moral situada a partir de la filosofía, pero especialmente de la religión católica, en la que se asigna a la educación la producción y moderación de dichos sentimientos: la dignidad, el deseo, la gloria, mediante el ejemplo y las buenas lecturas entre otras (S. A., 1894a, p. 52). Frente al deseo se expresan preocupados por cuanto reconocen que si bien su naturaleza es más espiritual, por lo que parece ser una inclinación o un sentimiento de un orden más elevado, no significa que todos los deseos sean buenos (S. A., 1894b, p. 167). Y se afirma que los sentimientos provienen y expresan distintos estados del alma dirigidos hacia otras cosas sin privarla de serenidad y libertad (p. 167). Las pasiones, en cambio, son afecciones excesivas y violentas que hacen sufrir o padecer al que las tiene (p. 167). Para el caso del amor, se afirma por ejemplo que este pertenece por un lado a la fisiología (o función natural de las sensaciones) y por el otro a la psicología (o aplicación moral de los sentimientos). El amor del lado de la fisiología pertenecería al esposo, que era quien desempeñaba el papel preponderante. A la esposa le correspondería el amor de la psicología, ya que ella era la encargada del papel psíquico: del amor así combinado "de su integridad experimental y sentimental, se deriva para el hombre y la mujer la felicidad completa" (Barral, 1921).

Los sentimientos en el orden moral se dirigían hacia el amor a la gloria y el patriotismo, acendrados especialmente en el hombre (Menéndez, 1902). Otros sentimientos, como el amor a la familia, al deber (Del Real y Mijares, 1907), a la compasión y todos los llamados tiernos o delicados resultaban del dominio de la mujer. Entre los sentimientos morales se encontraban el amor divino y la gratitud y el respeto sin límite hacia Dios, que debían enseñarse especialmente a las niñas (p. 257).

En la educación femenina se podía considerar la actividad intelectual como posibilidad de placeres intensos y goces hondos y permanentes desde donde podían surgir sentimientos como los artísticos y los científicos (Ingenieros, 1916). De allí la necesidad de que las educadoras sintieran y comprendieran la belleza en todas sus manifestaciones a la hora de forjar sentimientos estéticos en las discípulas, señalando la urgencia de desterrar de la escuela y sus alrededores todo lo feo, sucio y grosero (Del Real y Mijares, 1906).

En consideración a que la belleza pudiese ser un sentimiento moral y la mujer por instinto fuese amante de todo lo bello y delicado, se afirmaba que

\section{la belleza moral podía estudiarse y adquirirse en la escuela. Era menester entonces hacer observar a las niñas la belleza moral, verla en las acciones de sus compañeras, en las escenas de la vida de familiar para lo cual era urgente escogerles con sumo cuidado las lecturas entre las de los buenos autores procurando que fuesen comprensibles para ellas. (p. 647)}

De otro lado, el sentimiento del honor conduciría a los niños a aficionarse a todo lo que era elevado, honroso y verdadero, y a detestar lo que fuese bajo, malo y falso. La educación entonces tendría que inculcar en la niñez la buena doctrina del hombre: probidad, indulgencia y bondad (Gómez, 1896/1897). Para el caso de las niñas como depositarias del honor de la familia, se les habría de despertar el sentimiento de la propia dignidad, no permitiendo que oyeran ni sostuvieran conversaciones de cierto estilo (Del Real y Mijares, 1907).

Como se observa, para la época que nos ocupa los sentimientos en los seres humanos estaban claramente diferenciados según se hablara de mujeres 
o de hombres. En ellas predominaba la intensidad de los sentimientos; en ellos, la inteligencia y la voluntad, aunque fuesen iguales en el número de facultades. Por ejemplo en la mujer la imaginación imperaba en la inteligencia, en el hombre en cambio reinaba la razón (Del Real y Mijares, 1906). En tal sentido se señalaba lo improcedente de permitir que el sentimiento se desatase en el terreno pedagógico, apoyados en Spencer y Kant calificaban la educación pública o de los niños como desastrosa (Pardo, 1894), afirmación que fue matizada cuando los maestros hombres enviados al frente de guerra dejaron de ir a las escuelas, y ellas, las mujeres -necesarias para el magisterio- vieron en este oficio una posibilidad de desarrollo personal, autorizado por la Iglesia y vigilado por la familia y la sociedad toda.

El sentimiento del amor para la vida conyugal les correspondía a las mujeres principalmente, y en ellas alcanzaba la más alta perfección en la idea de cumplir con dignidad sus funciones de esposas (Barral, 1921). El sentimiento sexual en cambio, que era propio de los jóvenes irrumpía brutalmente en el marco de una educación doméstica femenina en donde habían germinado sin control las pasiones, llevándolas al desborde de la imaginación, y haciéndolas incapaces de situarse de manera positiva en la vida real (Barral, 1921).

Resulta interesante encontrar que a partir de los sentimientos morales constituidos cobró tal relevancia la urbanidad, especialmente para las niñas, ya que en ellas estaba, como en ningún otro, la enseñanza de la bondad del carácter y la sumisión:

\begin{abstract}
Desde el momento en que las niñas entran en la escuela se las debe habituar a tratar a sus compañeras con dulzura y dedicación, acostumbrándolas asimismo a hacerse útiles y agradables a las personas que las rodean, pues la verdadera urbanidad depende en gran parte de la bondad de carácter, y consiste principalmente en someternos a los gustos y deseos de los demás, y en preferir su comodidad y bienestar a la nuestra. (Del Real y Mijares, 1908)
\end{abstract}

\section{Enseñando a sentir lo correcto}

En la diferenciación que los discursos sostienen entre niños y niñas, los sentimientos enseñados a las niñas se movieron entre el sentido moral y el estético, en especial cuando ellas eran amantes por instinto de todo lo bello y delicado (Del Real y Mijares, 1906). Se debía comenzar - señalaban- con el sentimiento o virtud de justicia, tan olvidada para ese tiempo (Del Real y Mijares, 1907), luego era menester continuar con el sentimiento de dignidad pues las niñas eran las depositarias del honor de la familia, que estaba centrado en la castidad (p. 268).
De allí que fuese necesario atender en la escuela tanto a su enseñanza como a los contenidos. Por ejemplo, las prácticas corporales debían reglarse y supervisarse, el exceso de ellos podía excitarlas poniendo en riesgo la dignidad:

Haciendo referencia a las Orientaciones pedagógicas de María de los Ángeles, guerra sin cuartel a las palabras vulgares y groseras que a veces manchan los labios de las niñas durante los recreos, sobre todo si la profesora les permite entregarse a juegos violentos que las exciten demasiado, haciéndoles perder el sentimiento de su propia dignidad. (De los Ángeles, 1922)

Así, las lecciones propuestas en la escuela contenían diariamente la lección de moral y constante práctica de los deberes y los buenos sentimientos, independientemente de las lecciones de religión y moral, economía doméstica y urbanidad, entre otras (Dirección del Secretario de Instrucción Pública, 1899). La idea fundamental era hacerlas tiernas, virtuosas, delicadas, buenas, enseñándoles cómo se adoraba el hogar e infundándoles principios sólidos de caridad, amor y dulce fraternidad mediante el ejemplo antes que a partir de libros (Arias, 1911).

\section{¿Quiénes enseñan a sentir?}

Dicha obra es de tal grado de virtud que tiene que ejecutar un máximo de cultura, de nobleza, de sentimientos, de modales puros de la encargada de dirigir niñas.

$$
\text { G. Arias Mejía }
$$

Se afirmaba que las maestras debían contar entre las cualidades dignas de su oficio, las cualidades intelectuales y morales, los sentimientos delicados y el estricto cumplimiento del deber. Era el modo en que cautivaban a las alumnas que entraban en contacto con ellas: la sencillez, la modestia, la dignidad, la discreción, la exquisita cultura en su conversación y en su trato. Si bien la misión de las maestras era de nobleza, sacrificio, ternura y amor, y ella representaba el corazón de la vida doméstica y social, no se podía olvidar que lo más grande para la mujer era el trono erigido en el hogar, a la vez que los amplios derechos y libertades otorgados; era preciso reconocer la superioridad de sus dotes pedagógicas y abrirle un ancho espacio al estudio de las ciencias y al cultivo de las artes en pro de la conquista de las verdades desconocidas, para favorecer su acción a la hora de curar las dolencias humanas: "para que al mismo tiempo, que consuele al hombre en sus desengaños y tristezas, una la gloria que brindan el estudio y las acciones generosas, a su corona de grandeza y de inmortalidad" (Espinel, 1930). 
Sin embargo se rechazaba su participación en la dirección y educación de varones pues se reconocía y afirmaba que sus sentimientos eran distintos a los del niño y del hombre, lo que no les permitía formar más allá de los sentimientos de su propio sexo: “ ¿cuál es la razón para que [...] se encuentren muchas escuelas de varones dirigidas por mujeres, incapaces de inculcar en niños de cierta edad los deberes y derechos que impone la ciudadanía, los altos sentimientos de amor a la república?" (Boletín de Instrucción pública de Cundinamarca, 1916).

\section{¿Cómo enseñar sentimientos buenos?}

Si bien la consideración de un buen maestro es imprescindible y ello se entiende discursivamente como ejemplo de vida, se aceptaba el castigo como práctica corporal necesaria para sancionar, encauzar y controlar los sentimientos de la niñez que no dejaban de aparecer en la escuela. En tal sentido el castigo era clasificado como preventivo y coercitivo. Los castigos preventivos se entendían como aquellos que ayudaban a alejar a los niños de cometer faltas y contribuían a formar el hábito del orden y a fijar en su corazón los sentimientos del bien y de la virtud. Los propósitos por alcanzar desde los castigos preventivos eran, entre otros, el cumplimiento del deber, el buen ejemplo, la moralidad, la religiosidad, el decoro, la regularidad, la puntualidad, el amor, la jovialidad, la prudencia, la justicia y el desarrollo de la atención. A propósito del buen ejemplo del maestro, se afirmaba que conducía a la imitación, hacía ver en él un espejo límpido y sin mancha; y en relación con la moralidad, se esperaba que ella condujera a los niños al conocimiento y a la participación de todas las virtudes positivas, haciéndoles amar el bien y odiar el mal. (Gutiérrez, 1899)

La vigilancia como estrategia asidua y sistemática ayudaba al maestro a no perder de vista ni por un momento a sus discípulos obligándolos a estar siempre entregados al cumplimiento de sus deberes. De otro lado, se reconocía en la reconvención privada un valor poderoso en el corazón del niño, ya que su alta impresionabilidad le permitiría despertar en él los sentimientos de gratitud y honor que elevarían su ser moral haciéndolo fuerte a la hora de combatir el mal que provenía del mundo externo y de la pervertida condición humana. Su empleo tendría que hacerse con tino y prudencia para no deprimir el carácter, ni sublevar el amor propio, ni mover a la ira, ni acompañarse de la vergüenza y humillación; antes bien, se buscaba que inspirara amor, gratitud y buenos propósitos de enmienda, para lograr en la escuela paz, tranquilidad y progreso (Gutiérrez, 1899).

\section{¿Qué es el amor?}

El amor, se afirma, es un sentimiento natural que viene primero de los padres (Garcin, 1925), sin embargo la razón distingue en el amor un error de egoísmo y un error de altruismo, naturales pero que no por ello se pueden ignorar (Garcin, (1925). De otro lado, se define al amor como una virtud y un deber que viene de una sólida instrucción religiosa en la escuela y desde el maestro, que a su vez infunde odio hacia el vicio y temor a Dios salvaguardia de la conciencia moral (Pinilla, 1920). Como virtud que va más allá de los buenos modales, es una virtud que se hace hábito, fin último de la educación mediante una influencia lenta y gradual, proporcional a las necesidades humanas. El maestro ha de preferir la bondad y la templanza, la simpatía y la dulzura antes que la acritud, la represión, la aspereza y la fuerza, pues las primeras convidan al amor y las segundas a la aversión, la resistencia y la impostación (Monsalve, 1897b). El amor dirige las obras de misericordia a partir del amor a los semejantes, que ha de inculcarse en la niñez (Del Real y Mijares, 19074). Y es también el amor una inclinación de orden moral que puede ser mala o buena según se le oriente en la escuela (S. A., 1894b).

\section{Características del sentimiento amoroso}

Entre los discursos que circulan, el amor es bondadoso y empieza en el maestro, amor que le da gran poder (Dirección de Instrucción Pública, 1871). El amor se aprende con el ejemplo, así que es tarea tanto del maestro como del padre ser justos, humanos y benéficos. No se trata de dar limosna, sino de ser caritativo; las obras de misericordia alivian mucho más que el dinero, pues al amar, servir y dirigir a los otros, el amor y el servicio serán devueltos (Dirección de Instrucción pública, 1871). De allí que se señale que el amor se enseña con amor. En tal sentido, el maestro tiene el deber de arreglar su conducta, de manera que en su vida pública y privada sirva de modelo a los ciudadanos:

\footnotetext{
procurará, en consecuencia, mantener relaciones benévolas con todos los vecinos honrados y hablará con ellos sobre la buena educación de los niños, a quienes visitará cuando estén enfermos. En una palabra, se hará estimar de la sociedad en que viva y amar de los discípulos; será pundonoroso con firmeza de carácter y evitará so pena de remoción, el mezclarse con personas del mala reputación del lugar. (Dirección del Secretario de Instrucción Pública, 1899)
}

Podemos suponer que estos preceptos obraron para las mujeres maestras. 


\section{Amory distinción sexual}

Sin embargo se reconocía que aunque a los ojos de Dios uno fuese igual al otro, educar en el amor suponía reconocer la distinción sexual que tiene la naturaleza establecida. Por ello se señalaba la necesidad de huir de los extremos a la hora de educar, sobre todo a las mujeres: no solo hacer calceta y rezar, pero tampoco igualarla al hombre: "que si en el particular no exige superioridad de educación para un sexo respecto del otro, acusa perfectamente, según el destino especial de cada sexo, diferencias que no pueden desatenderse sin contrariar la obra del Creador" (Del Valle, 1893, p. 319). De allí que se sostuviese que existía un modo de educación para el hombre y otro para la mujer fundado en la organización y en el destino de ambos (Del Real y Mijares, 1906). Se insistía que aunque el espíritu femenino era igual en el número de las facultades al del hombre, no lo era en cuanto a su intensidad. En la mujer dominaba el sentimiento, en cambio en el hombre la inteligencia y la voluntad. Además, dentro de cada facultad primaria habían diferencias: en la inteligencia de la mujer imperaba la imaginación, en la del hombre la razón (Del Real y Mijares, 1906).

De acuerdo con esta disparidad se hace hincapié en que es la mujer el medio necesario de la transformación moral del porvenir, por lo que se hace necesario atender dos aspectos de gran relevancia: en primer lugar, que era educadora por excelencia.

\begin{abstract}
Es ella en todas las circunstancias de la vida la educadora de los saberes que le rodean, porque por la exquisita sensibilidad de que está dotada y por algo misterioso que en ella existe, hace que los que la conocen y respiran su misma atmosfera conviertan a ella todos sus corazones y pensamientos. (Delvasto, 1916)
\end{abstract}

Tiene autoridad que usa siempre para enseñar algo: reúne y colecciona nuevos vasallos para la iglesia de Cristo, moldea el corazón del niño, mueve al hombre al camino verdadero y enseña al anciano el amor de los goces del cielo. De allí que se considere que dicho apostolado, el de enseñar con autoridad, la hacen una verdadera maestra en el ejercicio de las virtudes cristianas y sobre todo y ante todo con abnegación (Delvasto, 1916). En segundo lugar, se insistía en que "no era menester renunciar al trono que por la ternura y el amor había conquistado, que su misma debilidad constituía su fuerza, para ser además la reina del hogar" (Mc Dowall, 1920).

Tres formas de ese amor se expresaron en los discursos. Uno de ellos fue el amor en las niñas: han de favorecerse las sociedades o agrupaciones de niñas desde donde se satisfagan las tendencias nacientes: simpatía, instinto de maternidad, instinto social; que la sociedad, la familia o la escuela apaguen o contraríen dicho instinto es desviarlas o matarlas o producir el efecto contrario (Mc Dowall, 1920), ya que es la principal misión de las niñas: "Amar, cuidar y proteger y hacer la vida grata a los que la rodean" (Del Real y Mijares, 1907, p. 268). De allí la necesidad expresa de "inspirar en las niñas desde sus primeros años el sentimiento de sus deberes y el amor a la familia" (p. 268). Otro fue el amor de los padres, quienes podían llegar a tiranizar a los hijos en nombre del amor, amarlos en espera de que fuesen como ellos. En este ejercicio son múltiples los errores que podían cometer muchas mujeres al no medir siquiera las consecuencias (Garcin, 1925): La ley del trabajo y del sacrificio se imponen, por lo cual amar a los hijos no significa protegerlos de estas leyes, al contrario se impone formar en ellas (Garcin, 1925). El último, el amor y el matrimonio, considerado indisoluble por naturaleza; esto hacía que se considerara que el amor conyugal era principio o fuerza que hacía de dos seres uno solo; que unía y elevaba a ser uno de los núcleos de que se formaba la sociedad, que a la vez que daba la felicidad y santificaba, aumentaba la honra y prosperidad de la patria (Restrepo, 1916). En el matrimonio, el esposo hacía uso moderado y prudente de su autoridad. Y lo que se esperaba era que en este vínculo la autoridad naciese del amor, del celo por el bien común y de la conducta digna, y no de una imposición altanera, de antipática severidad o de ridícula ostentación (p. 361).

\section{Educación del amor}

Si partimos de entender para el periodo investigado la educación general como la crianza, enseñanza y doctrina, cualesquiera que sea, que se da a los niños y los jóvenes y, de otro lado entenderla como el "desarrollo progresivo y sistemático de las facultades tanto físicas como intelectuales, y generales del hombre desde el nacimiento hasta la adolescencia" (Lleras, 1872, p. 309), y si además aceptamos a la pedagogía como el "conjunto de principios en que debe fundarse la educación y los medios de que deben valerse para obtener los que a esta ciencia se dedican" (p. 309), es necesario que se considere como objeto de la verdadera educación, el dar al alma y al cuerpo toda la perfección posible. Y esto se lleva a cabo a partir de la formación moral de los alumnos a cargo de un maestro recto en su juicio, grande en su alma, en su celo y abnegación a la función que tiene a su cargo (p. 309).

Con la anterior aseveración se proponía que la enseñanza del amor estuviera acompañada tanto del conocimiento suficiente de lo que constituía 
el bienestar de los niños como de los medios para lograrlo. Por esta razón, educar a las niñas - futuras madres - en la escuela resultaba prioritario (Johonnot, 1893), máximo si ellas se constituían en maestras. Así, la educación del amor debía empezar - señalaban - por el amor y la gratitud a Dios como parte fundamental de la enseñanza de la moral; este amor se explicaba a partir del deseo de asemejarnos a Él en todo lo posible, perfeccionando todas nuestras facultades para el bien, lo que requería de una idea clara y exacta de la justicia. Luego se tendría que proceder a educar en el amor a la verdad. Introducir a los niños en su búsqueda y manifestación mediante la propia palabra, la instrucción, el respeto y la obediencia a los superiores y en especial a los padres y maestros. Después, el amor al prójimo que se expresaba en la caridad y misericordia con los más débiles, bondad, dulzura e indulgencia. También era muy importante el amor a los deberes del niño en su casa; deberes del niño para consigo mismo, cuidado del cuerpo sin caer en la presunción, cuidado del espíritu, superioridad de lo moral sobre lo físico. Por último el amor a cumplir los deberes para con los demás, con los animales y las plantas. Llama la atención con respecto al proceso de expansión de la escolarización en la primera mitad del siglo xx, que no fue solo una institución social desde la cual controlar, evangelizar y construir unos sujetos deseados (Del Real y Mijares, 1906). Fue también un lugar de enseñanza del sentimiento amoroso.

En relación con la educación en el amor, la urgencia de vincular a las niñas a este proceso se mostraba constante: "La ley del 18 de marzo mandaba abrir, en cada parroquia de cada cantón, una escuela de niños, y donde se pudiera otra para niñas" (León, 1921, p. 113). Frente a la dificultad de abrir escuelas para niñas, no se hicieron esperar directrices en las que se ordenaba impartir dicha enseñanza en conventos de monjas, lo que no siempre se llevó a feliz término dados los escasos recursos de estas instituciones religiosas (p.113). De otro lado, no dejan de aparecer justificaciones que hablan de su importancia: "La educación del bello sexo que ejerce tan poderoso influjo en la sociedad, debe llamar la atención del Congreso para destinar a ella algunas rentas que no se reclamen por objetos más sagrados" (p. 113).

Se diferenciaron también dichas enseñanzas en torno al amor según fuese niño o niña:

Todos los meses: constantemente práctica de la caridad cristiana; que los niños sean dulces y cariñosos con los seres pequeños; que tengan paciencia con los pobres y los enfermos; que presten a estos los auxilios que les sea buenamente posible; que las niñas comprendan que esta es la más hermosa de las virtudes la más propia de la mujer y se acostumbre a cuidar a su casa y a amar a los suyos para que en ella reine la paz y la alegría, que cultiven flores y la obsequien a la Madre de todos los hombres; que los niños se acostumbren a la solidaridad que debe existir entre los buenos ciudadanos, a no hacer daño a nadie, ni por nada, a ayudar y cuidar lo que es del público como cosa propia. (Dirección del Secretario de Instrucción Pública, 1899)

\section{Amor y educación religiosa}

El niño tiene una alma reflejo de lo sublime, de lo infinito, de Dios, una alma que el maestro debe cultivar, modelar y perfeccionar cada día teniendo ante sus ojos el ideal divino.

\section{G. Pinilla}

Se hace la consideración de enseñar el amor desde la religión, reconociendo dos partes de dicha enseñanza. De un lado, la enseñanza de la religión dirigida a la inteligencia (De los Ángeles, 1922) o a la educación de la conciencia (Pinilla, 1920) y del otro, la enseñanza de la religión dirigida al corazón (De los Ángeles, 1922) o a la educación de la sensibilidad moral, que es donde residen las inclinaciones y los afectos (Pinilla, 1920). Responsabilidad grande del maestro y de la maestra:

Mil casos encontrarás en la vida, suficientemente poderosos, para demostrarte de que de nada o de muy poco servirá confiar la religión a la memoria de las niñas y despertar en su corazón afectos, los más tiernos y delicados, si en una plenísima convicción de ideas no viene a hacerlos sólidos y duraderos.

(De los Ángeles, 1922, p. 18)

Como se observa en la cita anterior, se trataba de servirse de la religión y de los ejemplos para ver en el semblante de las niñas "la llama de los afectos que las palabras de la maestra habían prendido en su corazón" (p. 21) por ello se insistía en la utilidad y necesidad de una enseñanza afectiva: "pero jamás olvides que para que esos afectos rindan provechosísimos frutos, han de echar hondas raíces en el fértil terreno de las ideas claras y concisas" (p. 21).

Así, el amor enseñado en la escuela desde la religiosidad y bien desarrollado en el corazón de los niños en general lograría que todos se mirasen como hermanos, toleraran sus mutuas debilidades y fundieran en una sola todas sus aspiraciones persiguiendo un mismo fin, además de considerar los claustros de la escuela como su propio hogar, engrandeciéndolo con las prácticas del bien y con el ejercicio de sus virtudes públicas y privadas (p. 21). 


\section{Amor, estética y sensibilidad}

Frente a la educación del amor como una inclinación considerada buena consideran algunos discursos la urgencia del "educador cristiano" de formar moralmente a los niños enseñándoles a "luchar contra sí mismos a dominar sus pasiones, a contrariar sus inclinaciones pervertidas a permanecer firmes y como insensibles a las incitaciones culpables y hacerse por el contrario sensibles a todo lo bueno" (Pinilla, 1920). Aunque se señala, de otro lado, que no se trata de comprimir su sensibilidad, al parecer se propone ganarle poco a poco a los gérmenes de pasiones perversas mediante la enseñanza de pasiones generosas y nobles (Pinilla, 1920), como la generosidad, la abnegación, la compasión, la ternura, la templanza y el amor (S. A., 1894b).

La educación de la imaginación forma parte de esa sensibilidad que era necesario encauzar, especialmente en ciertas niñas: "que hallarán en esta una fuente constante de belleza y de ilusiones para animar un poco su vida, excesivamente monótona y vulgar particularmente en las familias del pueblo y de la clase media." (Del Real y Mijares, 1906, pp. 640-641). De allí que las actividades escolares se ofrecen como posibilidad para esta educación:

Cuando vayamos con las niñas a paseo, haremos que se fijen en la hermosura de los campos, en la belleza que tiene un horizonte en el cual se unen a lo lejos el cielo y la tierra, en las formas diversas de los árboles, que no se sabe si tienen más gracia y elegancia cuando se nos presentan cubiertos con las primeras hojas de la primavera, o cuando ostentan su variada arquitectura, dibujando sus ramas desnudas sobre el fondo triste de un cielo de invierno: en el perfil de la montaña que limita por un lado el paisaje, en las flores, en los pájaros

\section{$[\cdots]$}

Los cuentos y las poesías cortitas que tengan un argumento o idea bella y al alcance de las niñas; son también un excelente medio de la educación de la fantasía. (Del Real y Mijares, 1906, pp. 640-641)

\section{El amor y la educación femenina}

La educación del amor se torna en algo fundamental a la hora de considerar la educación femenina. Allí cobra un lugar especial el objeto de la escuela: desenvolver todas las facultades físicas y espirituales de las niñas de una manera armónica y total, instruyéndolas y preparándolas para que puedan realizar cumplidamente su futuro papel de esposas y madres y educadoras de sus hijos (Del Real y Mijares, 1906). La escuela considerada como un mundo pequeño, como el lugar donde se prepara, se arregla, y destina a esas almas que están como tiernos tallos, brotándoles las hojas, las flores, los frutos y también espinas que pueden tanto "embellecerlos o ahogarlos en ese inmenso y obscuro jardín del mundo; y que en esos corazones infantiles existen en germen o se desarrollan las mismas virtudes y vicios que dominan a los hombres del mundo" (Gómez, 1916), tiene una función primordial. Debe la niña aprender allí a ser económica, laboriosa, digna, pura en sus pensamientos, palabras y obras, dulce, cariñosa e indulgente, sacrificando sus gustos y sus deseos a los gustos de los demás, cifrando su dicha en hacer buenos y felices a los que la rodean (Del Real y Mijares, 1907).

Visto desde otra arista, la educación femenina en el amor supuso una estrategia económica emocional en pro de encaminar dichos estímulos y energías del sentimiento amoroso en provecho del progreso y del trabajo: todo ello sin que el sentimiento y el cariño se desatasen por parte de las maestras, pues en él había que desconfiar (Pardo, 1894). Se desconfiaba pero se formaba a partir de una manera particular de entender el amor en este ejercicio educativo. Sirviéndonos de Foucault (1984), la economía expresa un deseo por el control de sí mismo en primera instancia y segundo por el uso mesurado de los placeres en clave moral. Una economía que la escuela y la sociedad deberán encargarse de enseñar.

\section{¿Qué es el amor femenino?}

Los discursos acerca de la mujer permean la enseñanza en la escuela, discursos en los que a la mujer se le comienza a considerar ya no solo como quien concibe y alimenta a los hijos, sino también como quien los educa, a ser la madre de su inteligencia y de su corazón, a velar amorosamente por las facultades intelectuales y afectivas del fruto de sus entrañas, porque de esos desvelos maternales depende el futuro del hombre y de las naciones. Como mujer además de madre, podrá ejerce también la más noble misión en el seno de la familia y de la humanidad. Misión de paz, de regeneración física y moral, de felicidad y concordia (Gómez, 1925). Sin embargo no son pocas las voces opuestas al trabajo de la mujer fuera del hogar, ya que lo consideran perjudicial para sus funciones de esposa y madre:

El esposo que regresa fatigado y en busca de consuelo al hogar como a un refugio a donde no llegan las agitaciones del mundo, se halla con una concejala, periodista o cualquier otra cosa, que le ofrece teorías abstrusas en lugar de caricias. (Gómez, 1925, p. 128) 
Afirman que esta enfermedad de "la empleomanía que saca a la mujer del hogar para mecanizarla" (p. 128) como una condición de posibilidad y que responde a la evolución ideológica de la humanidad, que impone un nuevo problema: "el apartamiento de la mujer del hogar" debe ser sin embargo atendida en procura de evitar que su labor primordial, la de ser madre y esposa, se vea menoscabada por fuerzas externas que no siempre protegen las constumbres y la naturaleza del sexo femenino.

A modo de conclusión parcial: la niña será muy seguramente en el futuro caudal de amor:

Madre y maestra de escuela todo el día y obrera a sus horas, para agregar el fruto de su trabajo a las entradas más fuertes de su marido. Es más que una fuente de bienestar y de alegría para la familia; es como el vivo manantial de la moral. (Simón, 1893, 428-429)

Y también "institutora cuyas lecciones jamás se olvidan, aun cuando la muerte haya cerrado ya los labios que las daban. Es quien enseña la ternura sin hablar de ella al prodigarla" (Simón, 1893).

\section{Las niñas traen el germen del mal}

La observancia de la niña como buena discurre en discursos de la educación del amor femenino diferenciado del de los niños, lo que no silencia aquellos que sostenían que las niñas traían el germen del mal:

La niña [...] aporta un legado de predisposiciones morbosas físicas y de predisposiciones morales e intelectuales, contra las cuales la educación tiene que luchar paulatinamente para cambiarlas en lo que de nocivo tengan; las exigencias sociales son un valladar insuperable en muchas sociedades aún para romper con ciertos hábitos, y todo conspira a que la mujer carezca del conveniente equilibrio orgánico que debe tener para llenar cumplidamente su deber de madre. (Del Valle 1893, p. 319)

Germen que urgía atajar mediante la educación, de lo contrario arruinaría una familia entera y con ella a la sociedad: "Para no hablar de muchos otros males, recordemos lo general que es el histerismo en el bello sexo" (p. 319).

No se hablaba del gran mal, sino de pequeños males, de mínimas manifestaciones que podían comprometer la felicidad de la familia si no se reconocían a partir de un atento examen y se trataban. De allí que actuara como fuerza el que se multiplicaran y mejoraran las escuelas; era necesario además de ser justo con ellas por cuanto tenían el mismo derecho a la instrucción como los varones, garantizar la formación de compañeras aptas para ser esposas que ayudaran a combatir el libertinaje y la taberna, buenas madres en la medida en que contribuyeran a devolver la fuerza, la salud, la moral y el optimismo de una raza degenerada (Simón, 1893, p. 429).

Al educar a las mujeres, se partía del postulado pesimista y contradictorio entre la ley moral y la ley intelectual de la mujer, pues era "más apta para su providencial destino cuanto más ignorante y estacionaria" (Pardo, 1894, p. 284) resultara. Por su parte, la educación masculina se inspiraba en el postulado optimista, el de la perfectibilidad humana que ascendía en suave y armónica evolución hasta realizar la plenitud de su esencia racional.

\section{Cómo se enseña el amor}

Respecto de la enseñanza del amor a las niñas en tanto se les diferenciaba por considerarse una tarea más delicada, se proponía hacerlas tiernas, virtuosas, delicadas, buenas; enseñándoles cómo se adora al hogar e infundiéndoles principios sólidos de caridad, de amor, de dulce fraternidad, obra más de ejemplo que de conferencias y de libros, para lo cual se exigía una maestra de virtudes excelsas (Arias, 1911).

Convenía educar en la humildad antes que en el orgullo, el desdén la altanería, la insolencia, la violencia, la ostentación, la presunción, la vanidad y la fatuidad; pues todas estas contribuían a la construcción de un amor propio desmedido (Baunard, 1926). En tal sentido era primordial que se vigorizara la voluntad mediante el culto a la religión, la patria, el arte y la ciencia, y el amor sagrado y sincero a la verdad, a la virtud, al deber y al honor (Mora, 1922), de lo que se desprendía el perfeccionamiento del carácter.

La pedagogía doméstica se constituyó en Colombia a finales del siglo XIX en uno de los ramos de instrucción que se impartió a las niñas en la escuela, de gran importancia a la hora de formar a las futuras mujeres y madres que la sociedad moderna requería y en especial de insuflarles una idea de amor. Su puesta en circulación en la escuela, así como los textos destinados a su enseñanza formaron parte de la legislación educativa que se promulgó, es el caso del Colegio de la Merced, fundado en 1832 en cuyo decreto y bajo el Título 6, Artículo 26: "Del método y libro por los cuales debe enseñarse" reconoce que deben enseñarse "los principios de moral y religión, por Villa Nueva; los de urbanidad, por Urcullu²; la

2 José Urcullu Allen (Bilbao, 1790-Lisboa, 8 de junio de 1852). Escritor, matemático, pedagogo, gramático y traductor español. La obra en mención es seguramente Lecciones de moral, virtud y urbanidad (Londres, 1826). Trabajó como traductor para el editor alemán Ackermann, quien quería apropiarse con obras impresas en español el recientemente abierto mercado librario hispanoamericano tras la ruptura del monopolio de 
economía doméstica, por el Catecismo publicado por Akerman" (Boletín de Instrucción Pública de Cundinamarca, 1915). Esta fue una importante producción que legitimó e hizo positiva su enseñanza, fue el trabajo adelantado por Martín Restrepo Mejía en Economía doméstica, que se constituyó en texto para las escuelas durante un importante tiempo y que discurrió en diversas publicaciones seriadas que los maestros leyeron y en los que la educación de las niñas se encaminó a la formación de mujeres en consonancia con el destino escrito para ellas.

\section{Educar a la mujer que habita en la niña}

La mujer debe ser la reina del hogar, pero sus armas son la dulzura y el amor.

\section{Del Real y Mijares}

Sorprende en tal sentido que la educación de las niñas fuese en tiempo futuro: "desplegad cada día y más las virtudes de la mujer cristiana, los recursos de la inteligencia, la fuerza de los sentimientos elevados y nobles" (Restrepo, 1916, pp. 305-360), y no por lo que era la niña, un ser con unas características concretas de su propio presente. A la niña que vive y se educa en la escuela con sus características de niña, no se le educa para el presente, se le educa para el futuro.

Educar a las niñas - afirmaban- requería de un lugar agradable lleno de plantas donde se jugara de verdad y semejante al hogar doméstico, en el que reinasen la felicidad y la educación moral y del sentimiento (Del Real y Mijares, 1906, p. 81), con una maestra cariñosa e inteligente, elegante, diligente, conocedora de sus discípulas, amorosa maternalmente - madre más que maestra-, que las hiciese felices, robustas, atentas al llamado de su profesora, indulgentes y buenas con sus compañeras, solo así —insistían- podía responderse al objeto de educar a la mujer, que era el de realizar cumplidamente su destino en la vida (p. 80).

Indulgencia, severidad, justicia, templanza, amabilidad y amor eran los sentimientos de los que una buena maestra haría gala (Del Real y Mijares, 1907, p. 259). De ella, de su ejemplo, aprenderían las niñas a comportarse (Del Real y Mijares, 1908, p. 96). Se afirmaba que la misión de la mujer en la sociedad era la de amar, cuidar y proteger a los que la rodeaban,

edición que antes establecía España. Compuso, así, numerosos catecismos (pequeños volúmenes en dozavo, ilustrados con grabados, de entre cien y ciento cincuenta páginas, que servían de introducción didáctica a diversas disciplinas) sobre materias científicas (Matemáticas, Geometría, Ciencias Naturales) y algunas humanísticas (Mitología) para dotar de libros de texto a las instituciones educativas que empezaron a abrirse en el Nuevo Mundo. http://es.wikipedia.org/wiki/ Jos\%C3\%A9_Urcullu pues se consideraba que eran ellas las depositarias, en gran parte, de la felicidad, del honor, del bienestar y la salud de todos los que la rodeaban. Ella, la niña hermana, la niña hija, la niña madre, la niña esposa, era el solaz del hombre que llegaba al hogar y encontraba la sonrisa y el cuidado de las mujeres de su hogar. "De aquí la necesidad de inspirar en las niñas desde sus primeros años el sentimiento de sus deberes y el amor a la familia" (p. 96).

Según lo anterior, ella debía ser la enfermera de todos los que sufrían a su lado, y en este punto tenía que recordar que muchas veces de sus cuidados, de sus desvelos y de su exactitud en cumplir las órdenes del médico dependía la vida de un ser querido, y que en muchos casos una palabra de esperanza, una frase cariñosa aliviaba tanto al enfermo como la medicina más eficaz (p. 96).

En fin, que la niña aprenda desde la escuela a ser económica, laboriosa, digna, pura en sus pensamientos, palabras y obras, dulce, cariñosa, indulgente, y que sepa sacrificar sus gustos y sus deseos a los deseos a los gustos de los demás cifrando su dicha en hacer buenos y felices a los que la rodean.

(Del Real y Mijares, 1907, p. 96)

Dicho de otro modo, la niña sería dichosa en tanto hiciera felices a los otros amándolos, cuidándolos; se trataba de educar el sentimiento amoroso en la niña desde el reflejo en los otros del amor que ella prodigaba.

\section{A modo de cierre}

Por encima de la condición infantil de la niña que va a la escuela está la figura de la mujer que una niña proyecta en el futuro. Esto es lo que se ve y resulta recurrente en diversos discursos que circulan por revistas y periódicos que se ocupan de la educación y también de la escuela. La escuela tiene como misión configurar una mujer en la niña que cumpla con las características que se esperan de ella, dado su lugar en la sociedad. De allí que lo que se comparte socialmente en familia y en la soledad de algunas lecturas permitidas es el modelo de sujeto femenino singular. Por ejemplo, se sostiene que, como encarnación del más prístino sentimiento en la mujer, el amor es la verdadera síntesis de todas sus virtudes y la varita mágica con que puede hacer vibrar, como un címbalo de plata, el corazón del universo (Bernal, 1921).

Pero, ¿de qué belleza se habla, qué virtudes se esperan, de qué complemento se trata? No se requiere que la mujer imponga las formas de su pensamiento, la belleza reside en su candor y fragilidad, en su bondad y suavidad, donde el hombre viene a apagar la sed de las horas febriles. "Si madre, si esposa, si 
virgen prometida, es, ella la débil, palanca de todos los esfuerzos humanos" (López de Meza, 1915, pp. 206-262). Entre sus virtudes aparece el recato, expresado en la intimidad de su alcoba al lado de su marido, sonriente y amorosa. Respetuosa de su condición y deseo de ser en el mundo

\begin{abstract}
piensa cómo debe ser en lo ordinario de la lucha humana, piensa cómo se camina, mirando apenas dos metros adelante. Para su amor le basta un hombre, para su idealismo una flor [...] Y cuando piensa en el hijo no se lo figura el sabio o el poderoso que imagina su padre, sino que juiciosamente borda los pañales y hace la canasta del futuro; si en la flor piensa, baja a su jardín y riega un rosal; y si de amores está nostálgica, se asoma a ver al transeúnte. Esta es la cualidad psíquica que hace de ella un tesoro de prudencia y de consejo: la de que sabe mirar de cerca y pensar en presente de indicativo. (López de Meza, 1915, pp. 260-262)
\end{abstract}

Este discurso de una educación en pos de una niña amorosa que se hará mujer cumplidora de su misión de madre, y esposa solícita emerge al lado de un discurso que favorece el trabajo femenino antes proscrito. Es importante que ella sepa trabajar, que muestre con orgullo que de su frente no solo se desprenden los olores de azahar sino gotas de sudor y que su voz en la casa del amor o en los bancos escolares no solo se oiga regañona y melosa, sino consoladora al lado del enfermo, y festiva y atrayente en el comercio de capitales o ideas. Se inaugura la idea del capital de trabajo femenino como factor central en la vida económica, y su producto en la riqueza nacional. Para los estudiosos esto supuso cambios importantes en la educación general, empezando por hacerla más práctica: más hechos tangibles que teorías asombrosas que contribuyeran a cambiar el lujo por el trabajo esforzado que encauzase las costumbres del país (Rincón, 1904).

El amor en esta nueva existencia femenina se señala a partir del evangelio que otros discursos no niegan, incluso apoyan: Dios le ha confiado a cada uno el cuidado de su prójimo, máxima que se le ha asignado a la mujer como poseedora de un amor inmenso, pues ella tiene una necesidad de extender su acción alrededor y derramar sobre los demás lo que rebosa en su corazón. Ese amor al prójimo que ella encarna hace posible su profunda paciencia frente a la ignorancia, la miseria o los errores de sus semejantes; así, para este periodo en que se adelantó la investigación, la mujer se constituye en la institutriz de los ignorantes, la hermana de la caridad de los pobres, la consoladora de los desgraciados y madre atenta y vigilante de sus hijos; como apóstol de los extraños los alivia, los socorre, los fortifica con la acción imparcial e infatigable de su caridad (Combes, 1921).

Las niñas en pos de su fin último como esposas y madres alimentan sus sueños, aprenden a ser mejores mujeres y se preparan a cumplir sus fines sociales: "Por fortuna la mujer entre nosotros no desconoce lo elevado de su misión, y más bien peca por su amor excesivo que raya a veces en indebidas contemplaciones, que en falta de cariño y de sacrificios cuando es madre" (Combes, 1921), "pero es lo cierto que las buenas madres son el primer elemento para el engrandecimiento de un pueblo" (Gómez, 1925, pp. 126, 127).

La educación define a la madre como educadora, educación que aprende del ejemplo de su madre pero también en la escuela desde sus maestras y las lecciones pensadas para ello (pp. 126, 127). El ejemplo, así como la formación en los hábitos y la reprensión de las propensiones egoístas, estimulando los buenos impulsos se aprende y se practican con los hijos (Johonnot, 1893). La madre haciendo acopio de su amor lo conduce por la senda del bien y de la verdad lo cuida como "del fruto de sus entrañas; imprime en su alma las primicias del amor de Dios y prepara la nueva generación que ha de esperar al Mesías" (Gómez, 1925, p. 127); sus afanosos desvelos cuidan del cuerpo del niño y sus virtudes y sentimientos forman su corazón Gómez Carrillo, Agustín. (1896/1897, p. 370). Al trabajar la mujer por la felicidad del niño trabaja también por su propia felicidad (Garcin, 1925, p. 144).

\section{Referencias}

Abbagnano, N. (1963). Diccionario de filosofía. México/ Buenos Aires: Fondo de Cultura Económica.

Badinter, E. (1891). Existe el amor maternal? Historia del amor maternal. Siglos XVII al XX. Barcelona: Paidos-Pomaire.

Bauman, Z. (2009). Amor líquido. México: Fondo de Cultura Ecoonómica.

Belli, S. e Íñiguez-Rueda, L. (2008). El estudio psicosocial de las emociones: una revisión y discusión de la investigación actual. Psico, 39(2), 139-151.

Burke, P. (1993). Formas de hacer historia. Madrid: Alianza.

Casado, C. y Colomo, R. (2006). Un breve recorrido por la concepción de las emociones en la filosofía occidental. $A$ Parte Rei. Revista de Filosofía, 47. Disponible en http:// serbal.pntic.mec.es/ cmunoz11/casado47.pdf 
Chóliz, M. y Tejero, P. (1994). Noedarwinismo y antidarwinismo en la expresión de las emociones en la psicología actual. Revista de Historia de la Psicología, 15, 91.

Corona, S. y Rodríguez, Z. (2000). El amor como vínculo social, discurso e historia: aproximaciones bibliográficas. Espiral: Estudios sobre Estado y Sociedad, 6 (17), 55.

Diker, G. (2006). El maestro como autor en la prensa pedagógica argentina (1958-1930). Cali, Colombia: Inédito.

Escolano, A. (2001). Sobre la construcción histórica de la manualística en España. Educación y Pedagogía, 29-30, 13-24.

Foucault, M. (1984). El uso de los placeres. Historia de la sexualidad. París: Gallimard.

Illouz, E. (2007). Intimidades congeladas. las emociones en el capitalismo. Buenos Aires: Katz.

Novoa, A. (Dir.). (1993). A impresa de Educacao e Ensino. Repertório Analítico (séculos XIX-XX). Lisboa: I. d. Educacional.

Ojeda, C. (2010). Discurso psicológico en la formación de maestros en Colombia primera mitad del siglo xx: la revista pedagogica de la escuela normal central de institutores (tesis de maestría). Universidad Pedagógica Nacional, Bogotá, Colombia.

Pérez-Delgado, E. y Sirera, F. (1992). Los sentimientos sociales y morales según T. H. Ribot. Revista de Historia de la Psicología , 13 (2, 3), 97-103.

Sáenz, J. (1999). Hacia una pedagogía de la subjetivación. Educación y Pedagogía, 9-10 (19-20), 99-123.

Simmel, G. (2005). La metrópolis y la vida mental. Recuperado de www.bifurcaciones.cl/004/reserva.htm.

Viñao, A. (1999). Sarmiento: Anuario galego de historia da educación. En U. L. Coruña (ed.). Las autobiografías, memorias y diarios como fuente histórico-educativa: tipología y usos (pp. 223-253).

Viñao, A. (2010). Memoria, patrimonio y educación. Educatio Siglo XXI, 28(2), 17-42.

Zaragoza, J. (2013). Historia de las emociones: una corriente historiográfica en expansión. Asclepio. Revista de Historia de la Medicina y de la Ciencia, 65(1).

\section{Fuentes primarias}

Acosta, S. (1905). Consejos a las mujeres. Revista El Gráfico, 268-269.

Arias, A. (1911). Concursos pedagógicos. Revista Nueva, $4(38$ y 39$), 1351-1352$.
Ayerbe, C. (1910). Concepto del director de Instrucción de Popayán. Revista de la Instrucción Pública de Colombia, 25, 27.

Barral, G. (1921). Del amor sentimental. El Gráfico, 538, 7-8.

Baunard, L. (1926). Grandeza y humildad. Revista Colegio de Nuestra Señora del Rosario, 21, 398.

Bejarano, J. (1919). La Psicología y el derecho penal moderno. Repertorio de Medicina y Cirugía, 4(1), 180-181.

Bernal, R. (1921). La mujer, estimuladora. El Gráfico, 538, 263.

Boletín de Instrucción Pública de Cundinamarca. (1915). $2(20), 12$.

Boletín de Instrucción Pública de Cundinamarca. (1916). Informe del Director General de Instrucción Pública de Cundinamarca al señor Gobernador del Departamento. 25 de febrero de 1915 a 25 de febrero de 1916. 3(22), 35.

Boletín de Instrucción pública de Cundinamarca. (1916). 3(25), 15.

Casas, V. (1923, 27 de noviembre). Discurso pronunciado por Don Luis María Mora en la clausura de estudios de la Escuela de Artes y Oficios de Cundinamarca. Boletín de Instrucción Pública de Cundinamarca, 9(90), 10.

Combes, P. (1921). La mujer, educadora social. Horizontes. $6,439$.

Cortázar, R. (1914). Boletín de Instrucción Pública de Cundinamarca. 1(2), 22.

De los Ángeles, M. (1922, julio). Orientaciones pedagógicas. Boletín de Instrucción Pública de Cundinamarca, 9(82), 18.

De los Ángeles, M. (1922). Orientaciones pedagógicas. Boletín de Instrucción Pública de Cundinamarca, 9(83), 21.

De los Ángeles, M. (1922).Orientaciones pedagógicas. Boletín de Instrucción Pública de Cundinamarca. 9(81), 30.

Decroly, O. (1925). Adolescencia. Crónica: conferencias del doctor Decroly, Sección V. Revista Pedagógica. 8(4), 157-158.

Del Real y Mijares, M. (1906). Escuela de niñas. Educación estética. Revista de Instrucción Pública de Colombia, 19, 79-81, 83-84, 640-641, 645-647.

Del Real y Mijares, M. (1907). Escuela de niñas. La instrucción en las escuelas de niñas. Revista de Instrucción Pública de Colombia, 21(7 y 8), 257-261, 268-269. 
Del Real y Mijares, M. (1908). Escuela de niñas. La instrucción en las escuelas de niñas. Revista de Instrucción Pública de Colombia, 23, 96.

Del Valle, F. (1893). Higiene de la inteligencia. Revista de Instrucción pública de Colombia. 1(1), 319.

Delvasto, M. (1916). La educación en la escuela primaria. Boletín de Instrucción Pública de Cundinamarca, 3(21), 5 .

Dirección del Secretario de Instrucción Pública (1899). El maestro de escuela Revista escolar. Año 1. No 1 y 2, pp. $22-23,43-44,52-53$,

Dirección del Secretario de Instrucción Pública (1899). El maestro de Escuela. Revista Escolar. 1(3), 95, 91, 96.

Dirección de Instrucción Pública. (1871). La Escuela Normal. Periódico oficial de instrucción pública. 1(1), 24.

Director de Instrucción Pública. (1871). Higiene moral. La Escuela Normal. 2(30), 480.

Espinel, A. (1930). Educación personal del maestro. Revista Acción Escolar, 1(7). 101-102.

France, A. (1923). Mujer moderna y mujer ideal. El Gráfico, 14(664), 815.

Franco, L. (1920). Tesis de grado: firmeza de carácter. Boletín de Instrucción Pública de Cundinamarca. 7(70), 54.

Gámez, A. (1896, 1897). Instrucción Pedagógica Centroamericana. Revista de Instrucción Pública de Colombia. 6(31-36).

Garcin, F. (1925). Pedagogía doméstica. Revista Pedagógica, 8(4), 143-145.

Gómez, G. (1925). La mujer y el hogar. Revista Pedagógica, $8(4), 126-128$.

Gómez, M. (1916). Castigos que deben usarse en la escuela. Boletín de Instrucción Pública de Cundinamarca. 3(30), 10.

Gómez, P. (1935). La educación femenina en Colombia. Revista Educación, 8, 655.

Gutiérrez, R. (1899). Sistema correccional de las escuelas primarias. El Monitor. Serie III. 26-27, 87-89.

Herbrand, R. (1910). Concepto del director de Instrucción del departamento de Nariño. Túquerres. Revista de la Instrucción Pública de Colombia, 25, 213.

Hoyos, V. (1910). Concepto del director de instrucción de Manizales. Revista de la Instrucción Pública de Colombia. 25, 29.

Ingenieros, J. (1916). Psicología de la curiosidad. Revista Moderna. 4(28), 465.
Jiménez, M. (1910). La educación física de la mujer. Revista de Instrucción Pública de Colombia. 25(4-12).

Johonnot, J. (1893). Pestalozzi. Revista de la Instrucción Pública de Colombia. 1(1), 276-277.

León, F. (1921). Escuela Normal de Bogotá. Revista Pedagógica, 4(4), 113.

Lleras, M. (1872). Pedagogía, nociones preliminares. La Escuela Normal. 3(90), 309.

López, L. (1915). La mujer es la armonía del hombre. Revista Cultura, 1(5), 260-262.

López, S. (1910). Concepto del director de Instrucción del departamento de Nariño Ipiales. Revista de la Instrucción Pública de Colombia. 25, 218.

Maragal, J. (1921). La danza. El Gráfico, 10-11, 17.

Martínez, M. (1932). La educación física. Revista Militar del Ejército, 22, 469.

Mc Dowall, R. (1920). Informe de tesis de grado de la señorita Isabel Silva. Boletín de Instrucción Pública de Cundinamarca. 7(70), 68.

Mejía, L. (1910). Concepto del director de Instrucción del Departamento de San Gil Santander. Revista de la Instrucción Pública de Colombia, 25, 112, 115.

Menéndez, R. (1902). El juego: sus funestas consecuencias. El Nuevo Tiempo, 180, s. p.

Monsalve, R. (1897a). Medios para aumentar la matrícula y asistencia diaria en las escuelas públicas. El Monitor, Serie 1, 5, 590 .

Monsalve, R. (1897b). Disciplina. El Monitor. Serie 1, 5, 243-244.

Mora, L. (1922). El Carácter. Revista del Colegio Mayor de Nuestra Señora del Rosario, 17, 137.

Mutis, A. (1903). Moralidad de costumbres y educación popular. Conferencia dictada delante de la Sociedad Pedagógica de Santander. Revista de Instrucción Pública de Colombia, 14(80-85), 333.

Ospina, M. (1920). "Conducta prudente de la mujer casada" - A la señorita María Josefa Ospina la víspera de su matrimonio. Revista Horizontes. 7, 198-204.

Pardo, E. (1894). La Educación del hombre y de la mujer (Memoria leída en el Congreso Pedagógico el 16 de octubre de 1892). Revista de Instrucción Pública de Colombia, 2(3), 292.

Pinilla, G. (1920). Educación de la actividad moral. Revista Pedagógica, 3(2), 46, 47, 48, 49.

Prevost, P. (1871). Del papel que desempeña la familia en la educación. La Escuela Normal. 1(10), 161. 
Restrepo, M. (1916). Pedagogía doméstica. Capítulo 3. La esposa. Revista de Instrucción Pública de Colombia, 28(112), 301, 305-306, 308-309.

Restrepo, M. (1916). Pedagogía doméstica. Capítulo 1. Los dos esposos. Revista de la Instrucción Pública de Colombia, 28, 185-186.

Rincón, E. (1904). Educación de la mujer. Revista Lecturas (Ciencia y Letras). 1(6), 50.

Robledo, E. (1904). Higiene psicológica. Revista Nueva. Literatura y Ciencias. 1(4), 114.

Rodríguez, H. (1910). Concepto del director de Instrucción de Quibdó. Revista de la Instrucción Pública de Colombia. $25,25$.

S. A. (1893). Sinopsis razonada de los principios de moral y de derecho. Revista de la Instrucción Pública de Colombia, 1(2), 64.
S. A. (1894a). Instintos. Revista de la Instrucción Pública de Colombia. 2(3), 52.

S. A. (1894b). Del corazón y de la sensibilidad humana. Revista de la Instrucción pública de Colombia. 2(3), 167.

S. A. (1899). Indisolubilidad del matrimonio. Revista de la Instrucción Pública de Colombia. 11, 608.

S. A. (1914). Consultas. Páginas Marianas. 2(2) 39.

Simón, J. (1893). Sección científica, de la influencia de la mujer y de su educación en las costumbres. Revista de la Instrucción Pública de Colombia. 1(2), 428, 429.

Toscano, A. (1920). Influencia de la mujer. Revista Atenea, 17.

Varona, E. (1899). "Juegos de la infancia". Carta a su sobrina, Ezequiela Lerma de Prats. El Monitor. Serie 3, 26-27, $162,163$. 